\title{
Utilisation and Perceptions of Cervical Cancer Screening Services
}

\section{Mercy Kokuro}

https://orcid.org/0000-0003-4472-4310

Kwapong Nursing Training College,

Ghana

mercykokuro@gmail.com

\author{
Abigail Kusi-Amponsah Diji \\ https://orcid.org/0000-0002-4591-4215 \\ Kwame Nkrumah University of Science \\ and Technology, Ghana \\ akamponsah.fahs@knust.edu.gh
}

\section{Abstract}

Cervical cancer is the second most frequently diagnosed and the fourth commonest cause of cancer death among women worldwide. Even though cervical cancer is preventable, its screening rate has been reported to be low in Ghana. To the best of our knowledge, no study has focused on the utilisation and perceptions of cervical cancer among women in their reproductive age in Ghana. The present study aimed at assessing the utilisation and perceptions of cervical cancer screening services among women who seek reproductive healthcare services. A descriptive cross-sectional study was carried out among women aged 18 years and above. Using a two-stage sampling technique, 369 participants were selected from 2 out of 4 eligible study sites. Data on the perceptions and utilisation of cervical cancer screening services were collected following ethical approval. The data were collected using both English and Twi versions of the questionnaire. The data were descriptively and inferentially analysed. A few of the participants had been previously screened for cervical cancer $(n=69 ; 18.7 \%)$, while a greater proportion of the participants appropriately perceived the screening benefits (> 70\%), and an equally greater percentage of them harboured negative perceptions which prevented them from engaging in such endeavours $(>80 \%)$. Significant differences in perception were, however, observed in two-fifths of the studied areas (6/14) among the screened and unscreened participants. Cervical cancer screening services were not utilised by the majority of the participating women. Screening was associated with socio-demographic characteristics such as marital status, parity, education, and employment status. Inappropriate perceptions on cervical cancer screening may account for the low utilisation of cervical cancer screening. Therefore, all-inclusive health education on the benefits of cervical cancer screening for both women and men should be a priority for stakeholders and all health organisations.

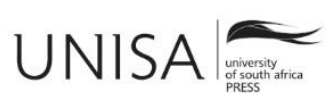


Keywords: cervical cancer; cervical cancer screening; utilisation; perception; women reproductive healthcare services

\section{Introduction}

Cervical cancer occurs when abnormal cells on the cervix grow uncontrollably resulting in a cauliflower appearance that bleeds easily upon contact (Smeltzer et al. 2010, 1457). It is the second most frequently diagnosed and the fourth commonest cause of cancer death among women worldwide (Bray et al. 2013, 1133). Almost 70 per cent of the global burden of cervical cancer occurs in areas of lower socio-economic levels (Bray et al. 2013, 1133).

The benefits of cervical cancer screening cannot be overemphasised. Current evidence shows that screening is associated with reduced incidences of cervical cancer (Boonpongmanee and Jittanoon 2007, 386) and consequent mortality as a result of early detection of precancerous lesions and the mitigation thereof (Adanu et al. 2011, 61; Peirson et al. 2013, 35). Nevertheless, the effectiveness of screening is dependent on the availability and accessibility of such services so as to detect abnormal smears for subsequent treatment.

Even though cervical cancer is preventable (Juckett and Hartman-Adams 2010, 1209; Luciani et al. 2009, 795), its screening rate has been reported to be low in Ghana (Adanu et al. 2011, 61; Ebu et al. 2015, 31; WHO/ICO Information Centre on HPV and Cervical Cancer 2007). As a result of this, several strategies have been put in place to increase the uptake of screening. Cervical cancer screening was introduced as a routine screening test for eligible women in all government hospitals in Ghana in 2008 free of charge by the Ministry of Health, with the aim of decreasing its mortality and morbidity. Recently, Awua et al. reported on a community-based self-specimen strategy which increased cervical screening uptake in a subdistrict in Ghana (Awua et al. 2017, 1).

The factors that affect women's decisions on and participation in cervical cancer screening are well documented in the literature (Lyimo and Beran 2012, 22; Udigwe 2006, 41; Winkler et al. 2008, 10-24; Wongwatcharanukul et al. 2014, 3753). Some of these factors include the perceived susceptibility to cervical cancer, the severity of the disease, the perceived benefits of screening, the accessibility and availability of services, fear of unknown outcomes of screening, comfort and privacy in health centres, attitudes of healthcare professionals, and the cost of services among others (Agurto et al. 2006, 85). One of the influential issues in embracing positive health behaviours, according to the health belief model, is gaining benefits from these behaviours (Adanu et al. 2011, 61; Hoque and Hoque 2015, 21). The main reasons given by 41 per cent of women who failed to participate in the cervical cancer screening programme, were the "lack of symptoms" and "not seeing the need for its screening" (Bessler, Aung, and Jolly 2007, 396). 
A few research studies have been conducted on the perceptions and utilisation of cervical cancer screening in Ghana (Abotchie and Shokar 2009, 412; Binka, Nyarko, and Doku 2016, 324; Opoku et al. 2016, 86). A cross-sectional survey of 410 female university students revealed fair perceptions of cervical cancer (Binka, Nyarko, and Doku 2016, 324). A quantitative study by Opoku et al. $(2016,86)$ which sought to examine the perceived risk factors of cervical cancer revealed poor perceptions of the risk factors of cervical cancer. Also, a study done on 140 female college students in Ghana reported that women perceived cervical screening to be beneficial, however, only about half of the women perceived themselves to be at risk of getting cervical cancer (Abotchie and Shokar 2009, 412).

Research studies on cervical cancer screening have mainly been carried out in developed countries with relatively few such studies in developing countries (Pollack et al. 2007, 57-63). Research studies on cervical screening are limited in Ghana (Abotchie and Shokar 2009, 412). Moreover, the researchers in previous studies have focused on socio-demographic factors that affect cervical cancer screening (Adanu et al. 2011, 59) and the cost of screening (Quentin et al. 2011, 379-389). To the best of our knowledge, no study has yet focused on the utilisation and perceptions of cervical cancer among women in their reproductive age in Ghana. Hence, the current study sought to assess the utilisation and perceptions of cervical cancer screening services among women who seek reproductive healthcare services in the Kumasi metropolis of Ghana.

\section{Materials and Methods}

\section{Study Design}

A descriptive cross-sectional quantitative design was considered appropriate in achieving the study aim.

\section{Study Area and Population}

The study was conducted in the Kumasi metropolis, the capital and the most populous of the 27 districts in the Ashanti Region of Ghana. The Kumasi metropolis has 4 government hospitals, namely Kumasi South Hospital, Manhyia Government Hospital, Tafo Government Hospital, and Suntreso Government Hospital. The reproductive health sections of these hospitals operate from 08:00 to 17:00 each week day (Mondays to Fridays) with an average daily attendance of 200 women. Cervical cancer screening is done at the reproductive health units of all 4 hospitals using the Papanicolaou smear test (Pap test) and visual inspection with acetic acid (VIA).

The study population consisted of women who were 18 years and older (adult females) and who were attending reproductive health services at the outpatients' department (OPD) in the two randomly selected hospitals (Kumasi South Hospital and Suntreso Government Hospital) within the Kumasi metropolis of Ghana. 


\section{Sampling Technique and Sample Size}

With the assistance of a biostatistician, a sample size of 332 was determined using the formula developed for cross-sectional studies with categorical variables for an unknown total population (Charan and Biswas 2013, 121-126). The standard normal variate was set at 1.96 at 95 per cent confidence interval; the probability of making a type I error ( $p$ value) was considered statistically significant at the 0.05 level (5\%) and the expected knowledge proportion in a population based on the previous study (p) was 68.4 per cent (Ebu et al. 2015, 31). A 10 per cent refusal or non-response rate was added to finally achieve the sample size of 369 .

In March 2016, the participants were selected using a two-stage sampling technique. Initially, the names of the four study sites were written and enclosed in sealed opaque envelopes; two of them were randomly selected from the four study sites to minimise selection bias. Within each of the two selected sites, a systematic sampling technique was used in selecting participants who agreed to participate. Using the average daily attendance of 200 women at each hospital, the kth number was calculated as $\mathrm{k}=\mathrm{N} / \mathrm{n}$, where $\mathrm{k}$ is the sample interval, $\mathrm{N}$ is the population (which was estimated at 200), and $\mathrm{n}$ is the sample size (which was estimated at 19 per day within the data collection period).

The first participant to be approached for each day was based on a random selection from 10 sealed opaque envelopes containing numbers from 1 to 10 . After randomly selecting one of the numbers, every eleventh woman who reported at the OPD of the reproductive healthcare section was selected to participate in the study until the required number for each day was attained. In general, 185 women were selected from Kumasi South Hospital, while 184 women were chosen at Suntreso Government Hospital.

\section{Data Collection Tool}

Owing to the non-existence of a validated questionnaire on the subject under investigation, the researchers developed a questionnaire based on the relevant literature. The face and content validity of the developed data collection tool was evaluated by seven healthcare professionals (two specialist physicians in obstetrics and gynaecology, three public health nurses, and two midwives) who had expertise in cervical cancer screening. The tool had an acceptable level of internal consistency as Cronbach's alpha values of .716 and .843 were recorded for both perception and utilisation sub-scales in a pilot study among 40 participants (20\% of average daily attendance) in a similar hospital. There were two versions of the questionnaires, one in English and one in Asante Twi. Asante Twi is a predominant local language in the Ashanti region of Ghana. With the assistance of a certified translator, the English version was translated into Asante Twi and back translated into English to ensure content integrity. The participants who were literate answered the questionnaires themselves whereas the less literate ones were assisted in completing them. 
Apart from the demographic characteristics, the questionnaire also covered the participants' perceptions and utilisation of cervical cancer screening. In order to avoid response bias, both positive and negative perception statements were rated on a 5-point Likert scale. Positive perception statements were rated from 1 to 5 , where 1 meant "strongly disagree", 2 denoted "disagree", 3 signified "neutral", 4 implied "agree", and 5 connoted "strongly agree". On the other hand, negative perception statements were rated from 5 to 1 , with the highest score of 5 representing "strongly disagree" and the lowest score of 1 denoting "strongly agree". A score of 1 was given to positive perception statements in which the participants agreed or strongly agreed, whereas a score of 0 was given to all other responses (neutral, disagree and strongly disagree). Negative perception statements in which the participants disagreed or strongly disagreed attracted a score of 1 , while a score of 0 was given to all other responses (neutral, agree and strongly agree). Hence, the minimum attainable positive score of the 14 perception items for each participant was 0 and the maximum possible score was 14 . For standardisation purposes, the participants' scores were converted into percentages using the formula: (obtained positive perception score/14) * 100 .

\section{Ethical Consideration}

Before conducting the study, institutional approval was sought from the Kumasi Metro Health Directorate, Ghana Health Service. Ethical approval was also obtained from the Health Research Ethics Committee of Stellenbosch University with reference number S15/10/229. Throughout the study, the researchers' conduct was guided by the following ethical principles: beneficence, non-malfeasance, confidentiality, privacy, anonymity, justice, informed consent, and autonomy. The participants' data were accessible to only the two researchers involved in the study. The participants were assured of privacy, anonymity, confidentiality and their right to terminate from the study at any point without having to explain themselves or receive penalties for doing so.

\section{Data Collection Procedures}

The researchers approached the participants while they were waiting to be attended to at the OPD of each hospital. The purpose of the study, its benefits and risks were explained to the participants as well as the voluntary nature of their participation. Selected participants who agreed to participate were assisted to answer the questions in a private area in the hospital or self-answered the questionnaires depending on their literacy level and preference for either the English or Twi version. In all, 165 participants answered the English version whereas 204 of them responded to the Twi version. A written informed consent form was also signed by the participants to serve as evidence for their voluntary participation and awareness of the study's procedures and protocols. The response time for completing the questionnaires was 15 to 30 minutes. 


\section{Data Analysis}

With the aid of the Statistical Package for the Social Sciences (SPSS) version 23.0., the data were analysed using descriptive and inferential statistics. Normally distributed continuous variable data were presented using means and standard deviations (SD), whereas medians and ranges were used for those with skewed distributions.

Categorical variables were illustrated using frequencies and percentages. The chi-square test of independence was also used to determine the association between any two categorical variables. The Mann-Whitney u-test (non-parametric) was used to compare the perceptions of cervical cancer screening among the two groups (screened and unscreened participants). For all analyses, the statistical significance was set at the 0.05 level.

\section{Results}

\section{Participants' Socio-demographic Characteristics}

The mean (SD) age of the participants was 30.9 (10.3) years and ranged from 18 to 64 years (refer to Table 1). A total of 46.1 per cent of them were single, and about twothirds of them (40.4\%) were married. Almost one-third of the participants $(29.3 \%)$ had given birth to only 1 child (primiparity) while over two-fifths (45.7\%) had given birth to 2 to 4 children (multiparity). With regard to their highest educational qualification, 41.5 per cent had received formal education up to the basic level (primary and junior high school) followed by 27.1 per cent of them who had received tertiary education. A little over two-thirds of the participants were employed (67.5\%) with the remaining being unemployed $(19.5 \%)$ or studying $(13 \%)$.

With the exception of the ages of the participants, there were statistically significant differences in the marital status, parity, highest educational level and work status between the screened and unscreened groups (see Table 1). A greater percentage of the women who had been screened were married, had given birth to one or more children, were highly educated and employed, relative to their unscreened counterparts.

\section{Utilisation of Cervical Cancer Screening}

Less than one-fifth (18.7\%) of the participants had been screened for cervical cancer in the past while the majority $(81.3 \%)$ of them had not been previously screened (refer to Table 1). 
Table 1: Participants' demographic characteristics $(n=369)$

\begin{tabular}{|c|c|c|c|c|c|}
\hline Variable & $\begin{array}{l}\text { Total }(\%) \\
(n=369)\end{array}$ & $\begin{array}{l}\text { Screened }(\%) \\
(n=69)\end{array}$ & $\begin{array}{l}\text { Unscreened }(\%) \\
(\mathbf{n}=\mathbf{3 0 0})\end{array}$ & $X^{2}(d f)$ & $p$-value \\
\hline \multicolumn{6}{|l|}{ Age of participants } \\
\hline $18-30$ & $214(58.0)$ & $36(52.2)$ & $178(59.3)$ & $5.493(3)$ & $0.117 \mathrm{~F}$ \\
\hline $31-45$ & $115(31.2)$ & $21(30.4)$ & $94(31.3)$ & & \\
\hline $46-60$ & $36(9.7)$ & $12(17.4)$ & $24(8.0)$ & & \\
\hline$>60$ & $4(1.1)$ & - & $4(1.3)$ & & \\
\hline Mean age (SD) & $30.9(10.3)$ & $33.0(11.4)$ & $30.3(10.0)$ & & \\
\hline Median age (range) & $28(18-64)$ & $30(21-60)$ & $28(18-64)$ & & \\
\hline \multicolumn{6}{|l|}{ Marital status } \\
\hline Single & $170(46.1)$ & $22(31.9)$ & $148(49.3)$ & $8.281(3)$ & 0.038* F \\
\hline Married & $149(40.4)$ & $37(53.6)$ & $112(37.3)$ & & \\
\hline Divorced/Separated & $16(4.3)$ & $2(2.9)$ & $14(4.7)$ & & \\
\hline Cohabiting & $34(9.2)$ & $8(11.6)$ & $26(8.7)$ & & \\
\hline \multicolumn{6}{|l|}{ Parity } \\
\hline Nulliparity (Para 0) & $58(15.7)$ & $4(5.8)$ & $54(18.0)$ & $7.307(3)$ & $\mathbf{0 . 0 4 3} * \mathbf{F}$ \\
\hline Primiparity (Para 1) & $108(29.3)$ & $22(31.9)$ & $86(28.7)$ & & \\
\hline Multiparity (Para 2-4) & $169(45.7)$ & $35(50.7)$ & $134(44.7)$ & & \\
\hline $\begin{array}{l}\text { Grand multiparity } \\
(\text { Para } \geq 5)\end{array}$ & $38(9.3)$ & $8(11.6)$ & $26(8.7)$ & & \\
\hline \multicolumn{6}{|l|}{$\begin{array}{l}\text { Highest level of } \\
\text { education }\end{array}$} \\
\hline None & 54 (14.6) & $14(20.3)$ & $40(13.3)$ & $15.762(4)$ & $\mathbf{0 . 0 0 3} * \mathbf{C}$ \\
\hline Basic & $153(41.5)$ & $15(21.7)$ & $138(46.0)$ & & \\
\hline Secondary & $62(16.8)$ & $12(17.4)$ & $50(16.7)$ & & \\
\hline Tertiary & $100(27.1)$ & $28(40.6)$ & $72(24.0)$ & & \\
\hline \multicolumn{6}{|l|}{ Work status } \\
\hline Employed & $249(67.5)$ & $55(79.7)$ & $194(64.7)$ & $11.814(2)$ & $0.003 * \mathbf{F}$ \\
\hline Unemployed & $72(19.5)$ & $4(5.8)$ & $68(22.7)$ & & \\
\hline Student & $48(13.0)$ & $10(14.5)$ & $38(12.7)$ & & \\
\hline
\end{tabular}

Note: $\mathrm{SD}=$ standard deviation, $\mathrm{F}=$ Fischer's exact test, $\mathrm{C}=\mathrm{Chi}$-square test, $*$ = significant values

\section{Participants' Perceptions of Cervical Cancer Screening}

As illustrated in Table 2, the participants generally had misguided perceptions of cervical cancer screening. The mean (SD) total positive perception of cervical cancer screening was 39.9 per cent $(16.6 \%)$ and ranged from 7.1 per cent to 100 per cent. No statistically significant differences $(p=0.614)$ were observed between the screened and unscreened group in the total positive perception scores.

The majority of the participants (> 70\%) correctly perceived the importance of cervical cancer screening in terms of assisting a woman to know her cervical health and cancer status as well as facilitating the cure process when premalignant lesions are detected early. On the other hand, 84.6 per cent of the participants felt screening was unnecessary as they believed there was no cure for cervical cancer. The majority of the participants 
perceived the cervical screening procedure as painful $(86.2 \%)$ and indicated that their partners would not want them to have the procedure done (87.3\%).

Significant differences in the perceptions were, however, observed in 6 out of the 14 studied perception areas (refer to Table 2). Relative to their unscreened $(77.3 \%)$ counterparts, a greater percentage $(89.9 \%)$ of the screened participants correctly perceived the detection of cervical cancer or otherwise as the purpose of screening $(p=0.039)$. A significantly higher proportion of the screened participants also perceived screening as a means of detecting premalignant cervical lesions $(p=0.045)$, being inexpensive $(p=0.021)$, and necessary as they believed the lesions were curable $(p=0.011)$. A greater percentage $(25.3 \%)$ of the unscreened participants, however, perceived cervical cancer as not being influenced by one's destiny $(p=0.015)$ and the screening procedure as being less painful $(p<0.001)$.

Table 2: Participants' perceptions of cervical cancer screening $(n=369)$

\begin{tabular}{|c|c|c|c|c|}
\hline Variable & $\begin{array}{l}\text { Total }(\%) \text { of } \\
\text { positive } \\
\text { perceptions } \\
(n=369)\end{array}$ & $\begin{array}{l}\text { Screened }(\%) \\
\text { positive } \\
\text { perceptions } \\
(\mathbf{n}=69)\end{array}$ & $\begin{array}{l}\text { Unscreened }(\%) \\
\text { positive } \\
\text { perceptions } \\
(\mathbf{n}=\mathbf{3 0 0})\end{array}$ & $p$-value \\
\hline $\begin{array}{l}\text { Cervical screening enables } \\
\text { a woman to know if she is } \\
\text { healthy (Agree) }\end{array}$ & $299(81.0)$ & 57 (82.6) & $242(80.7)$ & $0.272 \mathrm{C}$ \\
\hline $\begin{array}{l}\text { If cervical changes are } \\
\text { found early, they are } \\
\text { easily curable (Agree) }\end{array}$ & $282(76.4)$ & $60(87.0)$ & $222(74.0)$ & $0.230 \mathrm{C}$ \\
\hline $\begin{array}{l}\text { The purpose of screening } \\
\text { is to diagnose if I have } \\
\text { cervical cancer or not } \\
\text { (Agree) }\end{array}$ & 294 (79.7) & $62(89.9)$ & $232(77.3)$ & 0.039* C \\
\hline $\begin{array}{l}\text { Cervical screening can } \\
\text { detect cervical changes } \\
\text { before they become } \\
\text { cancerous (Agree) }\end{array}$ & $271(73.4)$ & $51(73.9)$ & $220(73.3)$ & $0.045 * \mathrm{C}$ \\
\hline $\begin{array}{l}\text { If a young woman goes for } \\
\text { a pap smear test, everyone } \\
\text { will think she is having } \\
\text { sex (Disagree) }\end{array}$ & $139(37.7)$ & $28(40.6)$ & $111(37.0)$ & $0.521 \mathrm{C}$ \\
\hline $\begin{array}{l}\text { Getting a cervical test } \\
\text { would only make me } \\
\text { worry or anxious } \\
\text { (Disagree) }\end{array}$ & $133(36.0)$ & $21(30.4)$ & $112(37.3)$ & $0.531 \mathrm{C}$ \\
\hline $\begin{array}{l}\text { I don't know where I } \\
\text { could go if I wanted } \\
\text { cervical cancer screening } \\
\text { (Disagree) }\end{array}$ & $120(32.5)$ & $14(20.3)$ & $106(35.3)$ & $0.057 \mathrm{C}$ \\
\hline $\begin{array}{l}\text { It is embarrassing to have } \\
\text { cervical cancer screening } \\
\text { (Disagree) }\end{array}$ & $107(29.0)$ & $19(27.5)$ & $88(29.3)$ & $0.051 \mathrm{C}$ \\
\hline
\end{tabular}




\begin{tabular}{|c|c|c|c|c|}
\hline Variable & $\begin{array}{l}\text { Total }(\%) \text { of } \\
\text { positive } \\
\text { perceptions } \\
(n=369) \\
\end{array}$ & $\begin{array}{l}\text { Screened }(\%) \\
\text { positive } \\
\text { perceptions } \\
(\mathrm{n}=69) \\
\end{array}$ & $\begin{array}{l}\text { Unscreened }(\%) \\
\text { positive } \\
\text { perceptions } \\
(\mathbf{n}=\mathbf{3 0 0})\end{array}$ & $p$-value \\
\hline $\begin{array}{l}\text { If a woman is a virgin, a } \\
\text { pap smear test will take } \\
\text { away her virginity } \\
\text { (Disagree) }\end{array}$ & $91(24.7)$ & $11(15.9)$ & $80(26.7)$ & $0.062 \mathrm{C}$ \\
\hline $\begin{array}{l}\text { It is too expensive to have } \\
\text { cervical cancer screening } \\
\text { (Disagree) }\end{array}$ & $85(23.0)$ & $21(30.4)$ & $64(21.3)$ & $0.021 * \mathrm{C}$ \\
\hline $\begin{array}{l}\text { If I am destined to get } \\
\text { cancer, I will get it with or } \\
\text { without screening } \\
\text { (Disagree) }\end{array}$ & $83(22.5)$ & $7(10.1)$ & $76(25.3)$ & $0.015^{*} \mathrm{C}$ \\
\hline $\begin{array}{l}\text { Screening for cervical } \\
\text { cancer is not necessary } \\
\text { since there is no cure } \\
\text { (Disagree) }\end{array}$ & $57(15.4)$ & $13(18.8)$ & 44 (14.7) & 0.011*C \\
\hline $\begin{array}{l}\text { Cervical screening is } \\
\text { painful (Disagree) }\end{array}$ & $51(13.8)$ & $5(7.2)$ & $46(15.3)$ & $<0.001 * \mathrm{C}$ \\
\hline $\begin{array}{l}\text { My partner would not } \\
\text { want me to have cervical } \\
\text { cancer screening } \\
\text { (Disagree) }\end{array}$ & 47 (12.7) & $7(10.1)$ & $40(13.3)$ & $0.019 \mathrm{C}$ \\
\hline $\begin{array}{l}\text { Overall perception of } \\
\text { cervical cancer screening } \\
\text { (14 items) } \\
\text { Mean (SD) } \\
\text { Median (Range) } \\
\% \text { Mean (SD) } \\
\% \text { Median (Range) } \\
\end{array}$ & $\begin{array}{l}5.6(2.3) \\
5(1-14) \\
39.9(16.6) \\
35.7(7.1-100) \\
\end{array}$ & $\begin{array}{l}5.5(2.2) \\
5(1-12) \\
38.9(15.7) \\
35.7(7.1-85.7) \\
\end{array}$ & $\begin{array}{l}5.6(2.4) \\
5(1-14) \\
40.1(16.8) \\
35.7(7.1-100)\end{array}$ & $0.614 \mathrm{M}$ \\
\hline
\end{tabular}

$\mathrm{M}=$ Mann-Whitney $\mathrm{U}$ test; $\mathrm{C}=$ Chi-square test analysis

\section{Discussion}

The current study assessed the utilisation and perceptions of cervical cancer screening among women who seek reproductive healthcare services in the Kumasi metropolis of Ghana. Our findings revealed that few of the participants had been screened for cervical cancer in the past. This low trend is similar to previous studies that have been conducted among different population groups in Ghana (Abotchie and Shokar 2009, 412; Adanu et al. 2011, 59; Ebu et al. 2015, 31). Nevertheless, our study seems to have a higher screening rate than previous reported studies in Ghana. This may be related to the fact that the majority of the studied participants had received formal education. The reported low cervical cancer screening uptake in our study is also consistent with findings from other diverse population groups in other countries (Ferlay et al. 2010, 2893; Kileo et al. 2015, 552; Mosavel et al. 2009, 114; Phongsavan et al. 2010, 821; Sudenga et al. 2013, 895; Utoo, Ngwan, and Anzaku 2013, 1). The generally low uptake of cervical 
cancer screening among women reiterates the need for effective strategies that will sensitise women and afford them an opportunity to partake in the exercise.

It was also revealed that the few participants who had been previously screened were mostly married, had given birth to one or more children, had received higher level of formal education and were employed. These findings are in agreement with many studies which reported that socio-demographics such as marital status, educational level, parity and work status influence women's choices and readiness to be screened for cervical cancer (Aswathy et al. 2012, 205-210; Ayinde, Ogunbode, and Adebayo 2005, 21-24; Nene et al. 2007, 264-272;). Consistent with previous studies (Ayinde, Ogunbode, and Adebayo 2005, 21-24; Mutuma et al. 2016, 94-99), the current study found that the screened participants were predominantly married. In the past, women with male partners who were supportive of cervical screening have also been reported as a significant predictor of screening behaviour (Thiel de Bocanegra et al. 2009, 326). The level of education has also been linked with screening behaviour: highly educated women are more likely to be screened (Mutuma et al. 2016, 94) while women with lower educational levels are less likely to be screened (Nene et al. 2007, 264). Women who are gainfully employed have been shown to stand a higher chance of being screened (Mutuma et al. 2016,94-99; Nene et al. 2007,264-272). This is not surprising considering that unemployed women may have to resort to other significant relations (such as mothers, fathers, uncles, and aunts) to be able to pay for their reproductive health services and other associated costs. Implicitly, unemployed women's lack of financial capacity could serve as a barrier to cervical cancer screening (Lyimo and Beran 2012, 22). Education in this area should consider these socio-demographic factors in the design and implementation stage to enhance screening uptake.

\section{Perceptions of Cervical Cancer Screening}

Akin to a previous study (Phongsavan et al. 2010, 821), the majority of the studied participants positively perceived the importance of screening in terms of assisting a woman to know her cervical health status and to initiate steps towards treatment upon early detection of premalignant lesions. To our amazement, a greater number of the participants wrongly perceived cervical cancer to be unnecessary as they believed it had no cure. In fact, earlier evidence over the past years proves that early detection of premalignant lesions leads to cervical cancer elimination (Adanu et al. 2011, 61; Peirson et al. 2013, 552).

A higher proportion of the participants also perceived screening to be painful as equally reported in a similar study in Jamaica (Bessler, Aung, and Jolly 2007, 396-400) in which pain was regarded as a major fear, and which inhibited screening behaviour. Cervical screening methods include VIA, Pap smear, liquid-based cytology, and HPV DNA testing (Almonte et al. 2007, 797; WHO/ICO Information Centre on HPV and Cervical Cancer 2007). Though the procedures involved in these techniques are known to cause some discomfort (Bessler, Aung, and Jolly 2007, 396), they are not expected 
to be painful. Pain experienced during these procedures may be related to other factors due to the complex and multidimensional nature of the pain experience (Ncube et al. $2015,111)$. The alleviation of this phobia can also be achieved through the sharing of experiences on the part of screened women to demystify these misconceptions.

Consistent with previous literature (Lyimo and Beran 2012, 12), a greater percentage of the participants indicated that their partners would not want them to have cervical cancer screening. This signifies that the majority of women are still not empowered to make decisions on their own including those regarding their health status. This is as a result of the patriarchal social system in Ghana and in many other African countries, where men dominate and are socially privileged to control households (Maisha 2016 n.d.). Women in the twenty-first century should be encouraged and empowered to make decisions on their own especially on issues regarding their health status.

The study revealed significant differences in 6 out of the 14 studied perception areas. A greater percentage of the screened participants correctly perceived screening as a means of detecting premalignant cervical lesions and cancerous ones, being inexpensive and important. They believed early detection of precancerous lesions were curable. These positive perceptions and their higher level of education might have influenced their screening behaviour (Mutuma et al. 2016, 94-99). An equally greater percentage of the unscreened participants, however, recognised cervical cancer as not being influenced by one's destiny and perceived the screening procedure as less painful compared to their screened counterparts. This further demonstrates that the fear of pain did not discourage the screened participants from participating in the procedure as found in Bessler, Aung, and Jolly's $(2007,400)$ study.

\section{Limitation}

Because multiparity is a risk factor of cervical cancer, we collected data from the point of reproductive healthcare in order to assess the participants' perceptions and screening uptake. We recognise this as a limitation of the current study and recommend future studies.

\section{Implications}

The current study has implications for healthcare, society and future research investigations. There should be an improvement in public education to raise awareness of cervical cancer screening among women and men nationally. Women in Ghana should also be empowered to take decisions concerning their health. Future studies should explore cervical cancer knowledge and awareness from both men and women in different geographical areas of Ghana. 


\section{Conclusion}

The utilisation of cervical cancer screening services is significantly low among women in the Kumasi metropolis of Ghana. Screening was associated with socio-demographic characteristics such as marital status, parity, education and employment status. Misguided perceptions of cervical cancer screening may account for the low patronage of cervical cancer screening. Implications of these findings for healthcare, society and future research studies have also been explored.

\section{Acknowledgements}

We would like to thank the participants and the management of the hospitals who gave permission for the study to be carried out in their facilities.

\section{Author's Contributions}

The first author conducted the data collection. Both authors analysed the data, prepared the manuscript, and approved the final manuscript.

\section{References}

Abotchie, Peter N., and Navkiran K. Shokar. 2009. "Cervical Cancer Screening among College Students in Ghana Knowledge and Health Beliefs." International Journal of Gynecological Cancer 19 (3): 412-416. https://doi.org/10.1111/IGC.0b013e3181a1d6de.

Adanu, R. M. K., J. D. Seffah, R. Duda, R. Darko, A. Hill, and J. Anarfi. 2011. "Clinic Visits and Cervical Cancer Screening in Accra." Ghana Medical Journal 44 (3): 59-63. https://doi.org/10.4314/gmj.v44i2.68885.

Agurto, Irene, Jorge Sandoval, Maribel de la Rosa, and Maria Elena Guardado. 2006. "Improving Cervical Cancer Prevention in a Developing Country." International Journal for Quality in Health Care 18 (2): 81-86. https://doi.org/10.1093/intqhc/mzi100.

Almonte, Maribel, Catterina Ferreccio, Jennifer L. Winkler, Jack Cuzick, Vivien Tsu, Sylvia Robles, Rina Takahashi, and Peter Sasieni. 2007. "Cervical Screening by Visual Inspection, HPV Testing, Liquid-Based and Conventional Cytology in Amazonian Peru." International Journal of Cancer 121 (4): 796-802. https://doi.org/10.1002/ijc.22757.

Aswathy, S., M. A. Quereshi, B. Kurian, and K. Leelamoni. 2012. "Cervical Cancer Screening: Current Knowledge and Practice among Women in a Rural Population of Kerala, India." Indian Journal Medical Research 136 (2): 205-10. Accessed on September 26, 2019 http://www.ijmr.org.in/downloadpdf.asp?issn=0971-5916. 
Awua, Adolf K., Edwin K. Wiredu, Edwin A. Afari, Ahmad S. Tijani, Gabriel Djanmah, and Richard M. K. Adanu. 2017. "A Tailored Within-Community Specimen Collection Strategy Increased Uptake of Cervical Cancer Screening in a Cross-Sectional Study in Ghana.” BMC Public Health 18 (1): 1-11. https://doi.org/10.1186/s12889-017-4631-y.

Ayinde, Olusola A., Olayinka O. Ogunbode, and Olatunde J. Adebayo. 2005. "Determinants of Cervical Cancer Knowledge and the Utilisation of Screening among a Nigerian Female Population.” Tropical Journal of Obstetrics and Gynaecology 22 (1): 21-24. https://doi.org/10.4314/tjog.v22i1.14535.

Bessler, Patricia, Maung Aung, and Pauline Jolly. 2007. "Factors Affecting Uptake of Cervical Cancer Screening among Clinic Attendees in Trelawny, Jamaica." Cancer Control 14 (4): 396-404. https://doi.org/10.1177/107327480701400410.

Binka, Charity, Samuel H. Nyarko, and David T. Doku. 2016. "Cervical Cancer Knowledge, Perceptions and Screening Behaviour among Female University Students in Ghana.” Journal of Cancer Education 31 (2): 322-327. https://doi.org/10.1007/s13187-015-0852-x.

Boonpongmanee, Chayanin, and Piyanuch Jittanoon. 2007. "Predictors of Papanicolaou Testing in Working Women in Bangkok, Thailand." Cancer Nursing 30 (5): 384-89. https://doi.org/10.1097/01.NCC.0000290804.38335.32.

Bray, Freddie, Jian Song Ren, Eric Masuyer, and Jacques Ferlay. 2013. "Global Estimates of Cancer Prevalence for 27 Sites in the Adult Population in 2008." International Journal of Cancer 132 (5): 1133-45. https://doi.org/10.1002/ijc.27711.

Charan, Jaykaran, and Tamoghna Biswas. 2013. "How to Calculate Sample Size for Different Study Designs in Medical Research?” Indian Journal of Psychological Medicine 35 (2): 121-26. https://doi.org/10.4103/0253-7176.116232.

Ebu, Nancy Innocentia, Sylvia C. Mupepi, Mate Peter Siakwa, and Carolyn M. Sampselle. 2015. "Knowledge, Practice, and Barriers toward Cervical Cancer Screening in Elmina, Southern Ghana." International Journal of Women's Health 7:31-39. https://doi.org/10.2147/IJWH.S71797.

Ferlay, Jacques, Hai-Rim Shin, Freddie Bray, David Forman, Colin Mathers, and Donald Maxwell Parkin. 2010. "Estimates of Worldwide Burden of Cancer in 2008: GLOBOCAN 2008.” International Journal of Cancer 127 (12): 2893-917. https://doi.org/10.1002/ijc.25516.

Hoque, E., and M. Hoque. 2015. "Knowledge of and Attitude towards Cervical Cancer among Female University Students in South Africa." South African Journal of Epidemiology and Infection 24 (1): 21-24. https://doi.org/10.1080/10158782.2009.11441335.

Juckett, Gregory, and Holly Hartman-Adams. 2010. "Human Papillomavirus: Clinical Manifestations and Prevention.” American Family Physician 82 (10): 1209-14. http://www.ncbi.nlm.nih.gov/pubmed/21121531. 
Kileo, Neema Minja, Denna Michael, Nyasule Majura Neke, and Candida Moshiro. 2015. "Utilization of Cervical Cancer Screening Services and its Associated Factors among Primary School Teachers in Ilala Municipality, Dar es Salaam, Tanzania." BMC Health Services Research 15:552. https://doi.org/10.1186/s12913-015-1206-4.

Luciani, Silvana, Barbara Jauregui, Clemence Kieny, and Jon Kim Andrus. 2009. "Human Papillomavirus Vaccines: New Tools for Accelerating Cervical Cancer Prevention in Developing Countries." Immunotherapy 1 (5): 795-807. https://doi.org/10.2217/imt.09.48.

Lyimo, Frida S., and Tanya N. Beran. 2012. "Demographic, Knowledge, Attitudinal, and Accessibility Factors Associated with Uptake of Cervical Cancer Screening among Women in a Rural District of Tanzania: Three Public Policy Implications." BMC Public Health 12:22. https://doi.org/10.1186/1471-2458-12-22.

Maisha, Z. Johnson. n.d. “160+ Examples of Male Privilege in All Areas of Life.” Everyday Feminism.” Accessed 17 April 2019. https://everydayfeminism.com/2016/02/160examples-of-male-privilege/.

Mosavel, Maghboeba, Christian Simon, Catherine Oakar, and Salome Meyer. 2009. "Cervical Cancer Attitudes and Beliefs - A Cape Town Community Responds on World Cancer Day." Journal of Cancer Education : The Official Journal of the American Association for Cancer Education 24 (2): 114-119. https://doi.org/10.1080/08858190902854590.

Mutuma, A. Muthoni, Otieno George Ochieng, Kei Robert Mburugu, Ndege Samson, Ndwiga Taratisio, Gacheri Rose. 2016. "Socio Demographic Characteristics Influencing Uptake of Screening for Cervical Cancer in Women Aged 18-49 Years in Imenti North Sub-County, Meru County, Kenya.” Science Journal of Public Health 4 (2): 94-99. https://doi.org/10.11648/j.sjph.20160402.13.

Ncube, Butho, Amita Bey, Jeremy Knight, Patricia Bessler, and Pauline E. Jolly. 2015. "Factors Associated with the Uptake of Cervical Cancer Screening among Women in Portland, Jamaica." North American Journal of Medical Sciences 7 (3): 104-113. https://doi.org/10.4103/1947-2714.153922.

Nene, B., K. Jayant, S. Arrossi, S. Shastri, A. Budukh, S. Hingmire, and R. Sankaranarayanan. 2007. "Determinants of Women's Participation in Cervical Cancer Screening Trial, Maharashtra, India.” Bulletin of the World Health Organization 85 (4): 264-72. https://doi.org/10.2471/BLT.06.031195.

Opoku, Constance A., Edmund Nii Laryea Browne, Kathryn Spangenberg, Cheryl Moyer, David Kolbilla, and Katherine J. Gold. 2016. "Perception and Risk Factors for Cervical Cancer among Women in Northern Ghana.” Ghana Medical Journal 50 (2): 84-86. https://doi.org/10.4314/gmj.v50i2.6. 
Peirson, Leslea, Donna Fitzpatrick-Lewis, Donna Ciliska, and Rachel Warren. 2013. "Screening for Cervical Cancer: A Systematic Review and Meta-Analysis." Systematic Review 2:35. https://doi.org/10.1186/2046-4053-2-35.

Phongsavan, Keokedthong, Alongkone Phengsavanh, Rolf Wahlström, and Lena Marions. 2010. "Women's Perception of Cervical Cancer and its Prevention in Rural Laos." International Journal of Gynaecological Cancer 20 (5): 821-26. https://doi.org/10.1111/IGC.0b013e3181daaefb.

Pollack, Amy E., Miranda Balkin, Lindsay Edouard, Felicity Cutts, and Nathalie Broutet. 2007. "Ensuring Access to HPV Vaccines through Integrated Services: A Reproductive Health Perspective." Bulletin of the World Health Organization 85 (1): 57-63. https://doi.org/10.2471/BLT.06.034397.

Quentin, Wilm, Yaw Adu-Sarkodie, Fern Terris-Prestholt, Rosa Legood, Baafuor K. Opoku, and Philippe Mayaud. 2011. "Costs of Cervical Cancer Screening and Treatment Using Visual Inspection with Acetic Acid (VIA) and Cryotherapy in Ghana: The Importance of Scale." Tropical Medicine and International Health 16 (3): 379-389. https://doi.org/10.1111/j.1365-3156.2010.02722.x.

Smeltzer, S. C., B. G. Bare, J. L. Hinkle, and K. H. Cheever. 2010. Brunner and Suddarth's Textbook of Medical-Surgical Nursing. 12th ed. Philadelphia: Wolters Kluwer.

Sudenga, Staci L., Anne F. Rositch, Walter A. Otieno, and Jennifer S. Smith. 2013. "Knowledge, Attitudes, Practices, and Perceived Risk of Cervical Cancer among Kenyan Women Brief Report.” International Journal of Gynecological Cancer 23 (5): 895-99. https://doi.org/10.1097/IGC.0b013e31828e425c.

Thiel de Bocanegra, H., C. Trinh-Shevrin, A. Herrera, and F. Gany. 2009. "Mexican Immigrant Male Knowledge and Support toward Breast and Cervical Cancer Screening." Journal of Immigrant Minority Health 11 (4): 326-33. https://doi.org/10.1007/s10903-008-9161-3.

Udigwe, G. O. 2006. "Knowledge, Attitude and Practice of Cervical Cancer Screening (Pap Smear) among Female Nurses in Nnewi, South Eastern Nigeria.” Nigerian Journal of Clinical Practice 9 (1): 40-43. http://www.ncbi.nlm.nih.gov/pubmed/16986288.

Utoo, Bernard Terkimbi, Stephen Dungbe Ngwan, and Ajen Stephen Anzaku. 2013. "Utilization of Screening Services for Cancer of the Cervix in Makurdi, Nigeria." Journal of Reproductive Biology and Health 1 (1): 1. https://doi.org/10.7243/2054-0841-1-2.

WHO/ICO Information Centre on HPV and Cervical Cancer. 2007. "HPV and Cervical Cancer in the 2007 Report." Vaccine 25 (Suppl 3): C1-230. https://doi.org/10.1016/S0264410X(07)01183-8.

Winkler, J., A. Bingham, P. Coffey, and W. Penn Handwerker. 2008. "Women's Participation in a Cervical Cancer Screening Program in Northern Peru." Health Education Research 23 (1): 10-24. https://doi.org/10.1093/her/cyl156. 
Wongwatcharanukul, Laead, Supannee Promthet, Peter Bradshaw, Chananya Jirapornkul, and Naowarat Tungsrithong. 2014. "Factors Affecting Cervical Cancer Screening Uptake by Hmong Hilltribe Women in Thailand." Asian Pacific Journal of Cancer Prevention 15 (8): 3753-756. https://doi.org/10.7314/APJCP.2014.15.8.3753. 